\title{
O TRABALHO DIDÁTICO DO PROFESSOR NO BRASIL DOS ANOS DE 1920: A AULA EM FOCO
}

\author{
Jose Carlos Souza Araujo \\ Universidade de Brasília \\ Universidade Federal de Uberlândia \\ jcaraujo@ufu.br
}

\section{RESUMO:}

O objeto desse artigo é esclarecer algumas categorias básicas do trabalho didático: primeiramente da intersubjetividade do professor e do aluno e, associadas a ela, as modalidades de ensino, os métodos de ensino, as técnicas de ensino, as tecnologias educativas, a avaliação, o tempo da operacionalização didática, comumente denominada por aula, o espaço físico, bem como os objetivos e as finalidades do ensino. Em sua segunda parte, este artigo reúne posicionamentos diversos e díspares a respeito do trabalho didático, de intelectuais da educação brasileira atuantes no cenário educacional brasileiro de 1920 a 1930, através de obras de caráter educacional e pedagógico. Trata-se, nesse sentido, de verificar o protagonismo do professor diante da organização do trabalho pedagógico e do trabalho didático.

Palavras-chave: Organização do trabalho didático; organização do trabalho pedagógico; aula; professor; profissão docente; Primeira República.

\section{THE PROFESSOR'S DIDACTICAL LABOUR IN BRAZIL AT THE YEARS OF 1920: THE FOCUS IN CLASS}

\begin{abstract}
:
The aim of this article is to clarify basic categories of the didactical work: firstly, with the intersubjectivity of the professor and the alumnus and, associated with it, the modalities, methods and techniques of teaching, to the educative technologies, to the evaluation, the time of the didactical operationalization, commonly denominated as teaching session, the physical area, and others purposes and intentions of teaching. On its second part, this article gathers various positionings and triggerings on the behalf of didactical work, of intectuallized people from the Brazilian Education that were relevant among the years of 1920 and 1930, through the publications of educational and pedagogical efforts. Finally, it treats to verify the relevance of the professor's position against the pedagogical labour organization and the didactical labour.
\end{abstract}

Keywords: Pedagogical labour organization; didactical labour organization; class; professor; teaching profession; Primeira República.

Em artigo anterior (ARAUJO, 2009), visou-se compreender os contornos da profissão docente associada desde o andamento da primeira revolução industrial aos nossos dias. Nele, três aspectos foram considerados como correlatos e inerentes à profissão docente: a participação da divisão do trabalho, a organização do trabalho pedagógico e a organização do trabalho didático. Buscou-se nesse sentido conceituar e historiar, pelas posições de diferentes autores clássicos europeus e brasileiros, tais locuções. Entre eles, encontram-se Kant (1993), Lakanal (1794), Herbart (1987), Buisson (1911), A. A. de Oliveira (2003), Lourenço Filho (1940) e Lorenzo Luzuriaga (2001). 
Em síntese, o percurso desenvolvido pelo referido artigo teve o objetivo de contextualizar, bem como lançar luzes sobre o período histórico-educacional brasileiro referente aos anos de 1920; além disso, também foi seu objeto conceituar, fundado em textos dos referidos autores, o que significou, em termos de construção histórica, a locução organização do trabalho pedagógico. Em suma: deparar-se com o verbete - organização pedagógica das escolas públicas - do Dicionário de F. Buisson (1911), foi algo que trouxe potencialidade a essa investigação, porque se revelou ele preocupado em responder às necessidades novas, tendo em vista o triunfo e a hegemonia da escolarização primária naquele momento na França.

Não é demais repetir que nessa conjuntura, o Brasil vivia a disseminação dos grupos escolares, bem como das escolas normais, associada à sua interiorização. Um exemplo estadual: Minas Gerais contava em 1920 com 02 escolas normais-modelo e 36 equiparadas às mesmas. Também em 1920, Minas Gerais contava, conforme estatísticas oficiais, com 166 grupos escolares instalados e, em 1930, com 265. Entretanto, a formação do professor em nível superior ainda inexistia no Brasil.

O objeto desse artigo é esclarecer algumas categorias básicas do trabalho didático: primeiramente da intersubjetividade do professor e do aluno e, associadas à ela, as modalidades de ensino, os métodos de ensino, as técnicas de ensino, as tecnologias educativas, a avaliação, o tempo da operacionalização didática, comumente denominada por aula, o espaço físico, bem como os objetivos e as finalidades do ensino.

Em sua segunda parte, este artigo reúne posicionamentos diversos e díspares a respeito do trabalho didático, de intelectuais da educação brasileira atuantes no cenário educacional brasileiro de 1920 a 1930, através de obras de caráter educacional e pedagógico. Trata-se, nesse sentido, de verificar o protagonismo do professor diante da organização do trabalho pedagógico e do trabalho didático.

\section{A organização do trabalho didático}

Uma locução que deixa o pesquisador intrigado é organização do trabalho didático, a qual, à primeira vista, parece se identificar com a locução, organização do trabalho pedagógico. Em outras palavras: haveria alguma diferença entre as organizações do trabalho pedagógico e do trabalho didático? Se sim, de que se constitui o trabalho didático?

Para enfrentar tal questão, pesquisadores brasileiros contemporâneos, vinculados ao campo da Didática, trazem algumas pistas a respeito e, dentre outros, além de Gilberto Alves (2005), vinculado ao campo histórico-educacional da Didática, devem ser observados os debates que estão postos por Luiz Carlos de Freitas (1995), Ilma Passos Alencastro Veiga (1996), Jose Carlos Libâneo (2004), Oder J. dos Santos (1986), Lílian Wachowski (1989). Ressalve-se que as discussões aí estabelecidas, presentes desde a segunda metade dos anos de 1980, estão referidas à organização do trabalho pedagógico e do trabalho didático.

Evidentemente, trata-se de fazer aqui uma ressalva: a de que não significa que a organização do trabalho pedagógico e a organização do trabalho didático não tenham se configurado anteriormente; ao contrário, é necessário compreendê-las como compartilhantes da constituição da escola moderna, se se inicia pela Ratio Studiorum, em elaboração desde os meados do século XVI. No entanto, parece plausível afirmar que as explicitações contemporâneas por pesquisadores brasileiros possam auxiliar na elucidação da questão em apreço.

Ressalte-se, também, que é possível uma história das organizações pedagógica e 
didática, o que lhe confere, de modo ímpar, sua historicidade. A favor de tal perspectiva, Sud Menucci, em a Crise da Educação Brasileira, cuja primeira edição é de 1930, traz uma plena orientação a esse debate, antes de se comentar as posições de pesquisadores contemporâneos:

Todos os rótulos, portanto, com que as escolas modernas vêm sendo apresentadas, não poderão esconder nunca, ao observador perspicaz e arguto, os dois pernos sobre que assentam. E as teorias filosóficas e os vistosos postulados sociológicos com que nos enchem a cabeça, para explicar-lhes a origem, não passam de justificações posteriores, surgidas lentamente da análise dos fatos e fenômenos sociais na hora em que se estão desenrolando. A verdade, porém, fica sempre no fundo: o sistema educativo, em vigor numa época determinada, é fruto e reflexo da organização do trabalho da sociedade a que serve. Quando este se modifica, a escola, isto é, aquele aparelhamento a que incumbe o preparo adaptativo da massa maior dos membros da comunhão, não pode fugir à fatalidade de transformar-se. E foi exatamente isso que aconteceu, no fim do século XIX e no começo do atual, naquela parte do globo que convencionou-se chamar-se a si mesmo "o mundo civilizado". (MENUCCI, 2006, p. 26-27).

Em relação às posições de pesquisadores brasileiros, aventada anteriormente, e em atenção ao objeto deste estudo, pode-se afirmar que, explícita ou implicitamente, o trabalho pedagógico e o trabalho didático são, por eles, reconhecidos como distintos. Evidentemente, suas diferenças se estruturam quanto aos vínculos mais ou menos radicais com a organização do trabalho no âmbito capitalista, cabendo ao trabalho pedagógico reproduzi-lo, também para mais ou para menos.

Quando se coloca no palco o trabalho didático, há certamente a compô-lo o trabalho pedagógico, o qual certamente tem um contorno mais amplo do que o primeiro, seja internamente à própria instituição escolar, ou mesmo externamente. Por outro lado, quando se coloca o trabalho pedagógico no palco, o trabalho didático se faz necessário em vista da própria efetivação da escola pela aula e pela sala de aula.

Em suma, pode-se afirmar com Ilma P. A. Veiga (1996), em resposta às questões em torno da organização do trabalho pedagógico, que a primeira ação

[...] para nortear a organização do trabalho na escola é a construção do projeto político-pedagógico assentado na concepção de sociedade, educação e escola que vise a emancipação humana. Ao ser claramente delineado, discutido e assumido coletivamente ele se constitui como processo. E, ao ser constituído como processo, o projeto políticopedagógico reforça o trabalho integrado e organizado da equipe escolar, enaltecendo a sua função primordial de coordenar a ação educativa da escola para que ela atinja o seu objetivo político-pedagógico. (p. 157)

Por outro lado, ao ver de Gilberto Alves (2005):

No plano mais genérico e abstrato, qualquer forma histórica de organização do trabalho didático envolve, sistematicamente, três aspectos: a) ela é, sempre, uma relação educativa que coloca, frente a frente, uma forma histórica de educador, de um lado, e uma forma histórica de educando(s), de outro; b) realiza-se com a mediação de recursos didáticos, envolvendo os procedimentos técnico-pedagógicos do educador, as tecnologias educacionais pertinentes e os conteúdos 
programados para servir ao processo de transmissão do conhecimento; c) e implica um espaço físico com características peculiares, onde ocorre. (p. 10-11)

Em síntese: estão aqui contemplados, além dos sujeitos (o professor e o aluno), o conteúdo, os métodos e as técnicas de ensino, as tecnologias educativas e o espaço físico. Entretanto, de acordo com Veiga (2008), haveria, além destes, outros elementos estruturantes da organização didática: a avaliação, o tempo (da aula), os objetivos e as finalidades de ensino.

Em relação ao trabalho didático, explicitado pelo planejamento e pela sua efetivação em aula, certamente os conteúdos guardam sintonia com as expectativas e com a sua inserção concreta em termos teórico-práticos - o que envolve a questão relativa aos objetivos e às finalidades; além disso, certamente há que se pensar na correspondência às necessidades e às intenções projetadas, e se a contribuição adéqua-se aos resultados esperados: a isso damos o nome de avaliação.

Estes aspectos constituem o cerne do trabalho didático ou, propriamente, o arranjo estrutural da aula, o que propicia afirmar que o trabalho didático envolve sistematização, organização, ordenação, coerência, metodização, coesão, logicidade, racionalidade, entrelaçamento - certamente do conteúdo, da metodologia, da avaliação feita, bem como dos objetivos e das finalidades esperados e concretizados. Tais substantivos em itálico, que expressam uma rede sinonímica plural entre eles, revelam semanticamente, nada mais nada menos, que harmonia, conexão, vínculo, união e nexo entre os aspectos que envolvem o arranjo estrutural do trabalho didático.

Nesse sentido, o trabalho didático, em âmbito escolar, é uma ação intencional que implica mutualidade, construída no interior da cultura ocidental, particularmente moderna, e projetada para se manifestar como uma mediação educativa. Em vista de sua própria constituição, espera-se que o trabalho didático também obedeça a tais critérios, ou seja: ela tem que dar a entender pelos seus sinais - objetivo, finalidade, conteúdo, método, técnica, tecnologia e avaliação, mediatizados pelo tempo e pelo espaço -, viabilizados pela sua operacionalização, que ela tenha uma direção, um sentido e um norteamento, que signifiquem alguma coisa para aqueles que dela compartilham enquanto sujeitos - os professores e os alunos.

Concebida como forma de comunicação, a aula revela-se como intersubjetividade, como interação, como inter-pessoalidade. Os sujeitos da aula realizam, intencionalmente, uma educação mútua: o professor aprende com o ensinar conteúdos, mas em vista do próprio aluno, o qual sinaliza sobre a sua própria aprendizagem, bem como sobre o ensino desenvolvido pelo professor.

Tal perspectiva - a da intersubjetividade - merece alguns esclarecimentos preliminares, uma vez que ela se realiza pela relação de vários sujeitos em vista do conhecimento, particularmente o de caráter sistemático e intencional, com o qual se envolve o trabalho didático. No dizer de Ferrater Mora, “[...] a intersubjetividade é uma espécie de ponte entre a subjetividade e a objetividade" (1982, p. 1746), mas ela é essencial aos sujeitos humanos: "A teia da sociabilidade não é uma circunstância casual, mas é substancial à essencialidade das pessoas. A sociabilidade não existe porque existem os entes individuais; estes é que só existem como humanos porque há sociabilidade" (SEVERINO, 2001, p. 55). E é em torno da compreensão dos mundos da natureza e da cultura que tal sociabilidade se elabora e se explicita pela aula.

Por outro lado, o trabalho didático deve assinalar um sentido ao ensino desenvolvido, edificando-o em torno da aprendizagem, da educação, da inserção na 
cultura, bem como partícipe do processo civilizatório. Nesse aspecto, o trabalho didático considerado como uma totalidade, passa a ser parte de um todo, posto que ele revela o seu termo assentado na educação, que visa a inserção do sujeito humano na cultura em vista da civilização. Destarte, o trabalho didático compartilha de uma totalidade social, posto que o processo cotidiano daquele, uma rotina essencial da escola, é a própria trama social: a aula não é o mundo, mas este se faz presente pela interlocução dos sujeitos da aula no interior da sala de aula.

Constrói-se, pela aula, possibilidades mediatas que se realizam em vista do desenvolvimento intelectual, do crescimento profissional, da formação moral - enfim a aula se traduz pelas janelas que se descortinam, em vista do futuro que se desenha a partir da própria intersubjetividade entre professores e alunos. Colocando o eu e o outro no palco, afirma Von Zuben que pela aula

[...] se desenrolam mais intensamente as articulações e contradições entre o eu e o outro, entre o passado e o futuro, entre a tradição e a revolução, entre a criatividade e o conformismo, entre a fala dialógica e a fala impositora, entre a difusão de idéias entre pessoas e a infusão de idéias sobre as pessoas. (2005, p. 125).

E é nesse sentido que comumente se destaca - não sem discussões, debates e polêmicas - a perspectiva política, expressa pela organização do trabalho pedagógico. Ela guarda uma relação com a pólis (em grego, a cidade) e, é por vínculo à noção de polis, que o termo político se explicita: polit é derivativo do termo grego pólis, enquanto envolve uma comunidade de indivíduos que realizam uma associação em vista da construção da própria história.

Nesse sentido, a intersubjetividade que se constitui, sistemática e organizadamente, por causa e em torno do denominado trabalho didático, percorre um caminho definido anteriormente como tecnia, o que envolve o saber fazer, o saber conduzir, o saber desenvolver a intersubjetividade sistematicamente planejada, organizada e intencionada. $\mathrm{E}$ tal intersubjetividade não se realiza através de encontros casuais, espontâneos, eventuais, ocasionais e involuntários. $\mathrm{O}$ trabalho didático que se realiza pelo encontro de sujeitos - é o contrário disso tudo.

E é porque é intencional, planejado, sistemático, voluntário, que o trabalho didático adquire uma amplitude que resulta em benefício da pólis. Enquanto instância cultural, edificada particularmente pela cultura ocidental, a escola através de seu trabalho didático tem o intuito de cimentar, entre outras dimensões, as relações humanas no interior de uma dada sociedade. A aula e o seu variável espaço denominado por sala de aula delineiam-se, em vista das novas gerações que por ela passam, como instâncias micro-sociológicas diferenciadas do núcleo familiar, dos encontros vinculados às práticas religiosas, às práticas folclóricas, ao lazer, aos movimentos sociais, às organizações da sociedade civil etc.

A aula e a sala de aula - esta oferece àquela o contorno espacial - como unidades da escola, e que se configura pelo trabalho didático em quaisquer níveis, têm uma perspectiva pública. Não é intencional à aula perspectivar a educação doméstica. A aula e a sala de aula promovem a constituição do sujeito humano para que se torne público, situando-o no âmbito dos conhecimentos sistemáticos de que compartilha a cultura. Trata-se de socializar a cultura sistemática herdada e construída, como se esta fosse um bastão a ser entregue pelas gerações capazes de exercer uma ação educativa, particularmente sobre as crianças, os adolescentes e os jovens. 
Nessa perspectiva, o desenvolvimento do trabalho didático implica em movimento e em historicidade. Porém, uma visão consolidada sobre o que é o trabalho didático pode ser inimiga dele mesmo: este é sempre planejado, objeto de adequações, proximamente preparado e vivenciado a cada aula no interior da sala de aula, um lugar de situações pedagógicas em que se vive a aventura de vivenciar o ensino, a aprendizagem, a educação, a cultura, a civilização etc.

No decorrer desse processo, os sujeitos se dialetizam, pondo à prova a subjetividade do professor e do aluno, bem como a objetividade de ambos. A intersubjetividade, por conseguinte, se realiza desde os âmbitos científico, pedagógico ou didático, mas não se restringem a estes. Associam-se aos mesmos as dimensões ética, política, estética, epistemológica, lógica. A retórica professoral só pode se sustentar adequadamente, se tais dimensões configurarem um sentido docente, e é este que o professor deve buscar.

Pensando-se ainda a partir do trabalho didático, ele é também gestor da história das gerações que pela escola passam, particularmente desde a democratização da escola em processo, mas em descontinuidade nos diferentes países e regiões, nas diferentes idades, como é o caso do Brasil. Por ela, circulam diferentes gerações que estabelecem interlocução em torno de utopias, projetos, desobediências, disciplinas e indisciplinas, entusiasmos e alegrias, tristezas e fracassos.

Nesse patamar, seja a aula considerada um exercício de poder pelo professor, que representa a cultura ou a geração adulta a atuar sobre as jovens gerações, seja ela um serviço a remediar os males da sociedade capitalista ou as dificuldades que esta imprime ao sujeito humano, seja a aula um serviço à sociedade capitalista, ao seu progresso, à afirmação do indivíduo, o que importa é que o trabalho didático possua um saber para quê, um projeto a construir a humanidade, mas um projeto que não seja metafísico e que enfrente os obstáculos contemporâneos à interlocução dos sujeitos. E a sociabilidade, sob o capitalismo é, certamente, um deles. O trabalho didático é movimento, e é co-partícipe do movimento da história presente, mas tem em vista o futuro da polis, ainda que a tecnia seja ou esteja descuidada, ou que a interlocução dos sujeitos não seja apropriada.

\section{A organização do trabalho didático em suas balizas históricas}

Primeiramente, algumas observações sobre as modalidades de ensino denominadas por individual, mútuo, misto e simultâneo. Em vista do período escolhido, em termos de modalidade de ensino, o Brasil dos anos de 1920 praticava o ensino simultâneo. Historicamente, é em vista da ampliação da escolarização, que nasce, ao final do século XVIII, o ensino mútuo ou monitorial - o qual irá substituir gradualmente o predomínio do ensino individual. Mas este ainda se faz presente na transição do século XIX para o século XX (um exemplo entre outros, Alceu Amoroso Lima). Entretanto, é a partir dos meados do século XIX que se generaliza o ensino simultâneo, época em que a escolarização primária se apresenta mais adensada em alguns países europeus, propiciando-lhes a superação do analfabetismo já no início do século XX.

Embora as três modalidades de ensino possam ser compreendidas como diversas quanto à organização do mesmo, na verdade acarretam em relações diferenciadas, envolvendo mais que o aspecto organizativo do ensino, posto que o professor e o aluno estabelecem-se intersubjetivamente através de interações diferençadas.

Qualificando o ensino individual como modo de ensino, a obra de um maranhense, publicada em 1874, analisava o ensino individual da seguinte maneira: "[...] o mestre leciona seus alunos uns após outros, jamais pôde ser praticado em escolas numerosas, pelo que raros são os seus partidários. A fadiga do mestre, a brevidade das lições, a perda 
de tempo que não obstante ocasiona, a emulação que tira aos alunos, as dificuldades que põe a disciplina, são os motivos do seu descrédito" (OLIVEIRA, 2003, p. 256).

Em linhas gerais, através do ensino mútuo "[...] se instruía ao mesmo tempo a muitos alunos com poucos professores, ficando os primeiros sob o cuidado dos chamados monitores. O sistema se estendeu rapidamente pelo aumento da população devido à Revolução Industrial e à necessidade de atender rapidamente ao seu ensino" (LUZURIAGA, 2001, p. 54-55). Portanto, desenvolvia o ensino mútuo uma instrução dos alunos pelos próprios alunos ou monitores - daí advém a denominação de ensino monitorial -, sob a direção de um só professor.

Também a posição do referido maranhense a respeito do ensino mútuo é significativa: afirmando que este é capaz de produzir milagres, posto que um só professor pode ensinar 300 meninos, justifica: "É mister, pois, que o professor evite essa tendência [...] de delegar quase todos os seus poderes nos monitores. Explique ele próprio o que for mais interessante e delicado, e deixe aos monitores só o que estes houverem feito prova de saber perfeitamente" (OLIVEIRA, 2003, p. 257).

Em tal posição, sobressai a necessidade de uma fusão entre o ensino mútuo e o ensino simultâneo, o que implicava na qualificação de ensino misto, uma vez que este

[...] altera a simultaneidade e mutualidade do ensino com o fim de obviar os inconvenientes, quer do modo simultâneo, quer do mútuo. Segundo o modo misto o mestre divide seus alunos em certo número de classes e dá sucessivamente lição a todas, fazendo entretanto que aquelas com que ainda não pôde ocupar-se, ou com que já se ocupou, em vez de ficarem entregues a si mesmas, estejam a estudar sob a direção de repetidores (Idem, p. 256).

Por sua vez, o ensino simultâneo vige na educação escolar ocidental desde os meados do século XIX até os dias de hoje. Em termos relacionais, reúnem-se o professor e os alunos, e sob a orientação do primeiro, explicita-se, conforme a concepção tradicional, a transmissão do conhecimento simultaneamente a um grupo de alunos. Tal como no ensino individual, ao professor cabe o papel central na atividade de ensino, mas diferentemente dele, o simultâneo implica em uma ação de caráter coletivo, e reúne as interações no interior de um grupo de mais ou menos quarenta alunos - como é comum hoje - com um professor. Nessa direção, trata-se, a um só tempo, de atender as exigências individuais dos alunos sem perder de vista a dimensão coletiva do trabalho docente.

Em segundo lugar, cabe compreender a respeito dos métodos de ensino. Em termos de suas concepções diretoras, estiveram em vigência e ainda se mantêm significativamente sob a tutela do ensino simultâneo, dando-lhe sustentação, o método tradicional, que se associou posteriormente ao método intuitivo, emergente este em âmbito escolar nos anos de 1870. Nesse aspecto, tal movimento se encontra no andamento da segunda metade do século XIX. Entretanto, sob os auspícios do movimento da Escola Nova, desde os fins do mesmo século, o método ativo ganhou relevância teórico-prática, dada a crítica aos métodos tradicionais e à emergência de alternativas, qualificadas como métodos novos, aqui denominados pela locução método ativo.

Desvendar o que constitui o método tradicional de ensino, seria necessário buscar desde as práticas e as concepções antropológicas que vieram estruturando historicamente a formação humana. Certamente, desde que a educação foi intencionada - e ela é inerente à existência humana - aí estava presente o método. Dessa forma, a imitação, a disciplina, a repetição, a memória, a autoridade, o hábito, o verbalismo, o intelectualismo são, entre outros, pilastras de tal método. Sua história e a sua crítica ganharam significação com a Revista HISTEDBR On-line, Campinas, n.35, p. 250-271, set.2009 - ISSN: 1676-258 
generalização da escola pública, obrigatória, gratuita e universal nos últimos 150 anos. Por conseguinte, buscar conhecê-lo em detalhes implica em conhecer a história da escola desde então aos nossos dias.

O método intuitivo, diferentemente do tradicional que é de caráter verbal, está assentado nos sentidos, contemplados como sustentáculos para o desenvolvimento do ensino, pois se trata de potencializar a faculdade da intuição que busca discernir independentemente do raciocínio e da análise. Historicamente, a defesa da intuição como fundamento metodológico de ensino emerge no período do Renascimento, e é constantemente retomada pela pedagogia no decorrer de sua história desde então aos nossos dias, e que se expressa contemporaneamente também pelos processos audiovisuais de ensino.

$\mathrm{O}$ ensino concreto, vinculado à vida, voltado para os aspectos utilitários do conhecimento (VALDEMARIN, 2004, p. 179), centrado na educação dos sentidos caracterizam a direção do método intuitivo, bem como a sua significação na história da pedagogia. Nesse particular, a obra do A. A. de Oliveira, o maranhense, situa concisamente a defesa do método intuitivo, considerando o método vigente no Brasil de então 'abstrato, longo e penoso'. Em relação ao método intuitivo, a citação a seguir, embora longa, dispensa comentários, além de se constituir lapidarmente esclarecedora:

O menino esquece facilmente o que se lhe disse ou ele disse, mas não o que fez ou viu fazer. Se isso prova que o menino só vive pelos sentidos, ou não forma idéia senão do que toca, experimenta e observa, todas as idéias devem-lhe ser comunicadas pelos sentidos. Mostre-se-lhe os objetos, que se lhe quer dar a conhecer. Siga-se do baixo para o alto, do pequeno para o grande, do semelhante para o dessemelhante, do conhecido para o desconhecido. Ou substitua-se a coisa à definição, à realidade, às fórmulas, o exemplo à regra, de modo que as idéias, que se lhe transmitirem, sejam exatas, claras e precisas a ponto de por assim dizer ele ver $e$ tocar os seus elementos nos objetos que se lhe mostram. Nesse gênero não conheço nada melhor que o método americano (OLIVEIRA, 2003, p.243).

Com relação ao método ativo ou experimental, ele se expressa pelo fazer do aluno, pelo estímulo à sua auto-atividade, o que envolve a sua iniciativa. Tal método teve a sua disseminação através do movimento da Educação Nova, emergente nos finais do século XIX, e consolidado desde as primeiras décadas do século XX. Os métodos ativos são vários, envolvendo apenas individual ou coletivamente os alunos, ou combinando o trabalho individual e o coletivo. Há também o método de trabalho por grupos, que se insere entre as modalidades de método ativo. Por conseguinte, diferentemente dos chamados métodos tradicionais, os métodos novos - traduzidos pela locução método ativo ou método experimental - deslocam-se da centralidade convergente em torno do professor, para pôr em foco o aluno. Assim, a liberdade deste torna-se o leitmotiv do processo escolar.

Com base na liberdade, configuram-se associadas à mesma a espontaneidade, a criatividade, a experiência, a iniciativa, a atividade, a individualidade, a necessidade, o interesse - todas tomando como base o aluno -, e expressam o desacordo teórico-prático com os métodos tradicionais centrados na imitação, na disciplina, na repetição, na memória, na autoridade, no hábito, no verbalismo, no intelectualismo, como se viu 
anteriormente. Na verdade, no interior desse desacordo de ordem metodológica, que revela a ponta do iceberg, estão em disputa concepções humanistas diversas, basicamente situáveis como tradicional e moderna, se se leva em conta que "[...] os métodos supõem sempre uma certa atitude em relação à natureza humana" (ULMANN, 1987, p. 7).

Em terceiro lugar, cabem alguns comentários às técnicas de ensino, as quais também se conjugam à historicidade do trabalho didático desenvolvido pela escola. Como os métodos estão associados às técnicas de ensino, faz-se necessário compreendê-los para além de suas heterogeneidades específicas. Ou seja, há uma diversidade de classificações que se envolvem em distinções preocupadas com as particularidades e com as peculiaridades metodológicas do ensino.

Didaticamente, o método envolve o concurso de processos que viabilizam o ensino. Para Cervo \& Bervian (1976, p. 33), preocupados com a metodologia científica, “[...] $o$ método é a ordem que se deve impor aos diferentes processos necessários para atingir um fim dado ou um resultado desejado". Dessa forma, o método envolve processos, permitindo-se afirmar que ele deve ser compreendido como um conjunto de processos que se ordenam em vista do ensino e da aprendizagem. Afirmando-se as técnicas como um conjunto de procedimentos devotados ao ensino e à aprendizagem, o esforço de distinção entre o método e a técnica de ensino fica facilitado, se se compreende a técnica como um modo de fazer, que contém diretrizes e orientações, e que visa a aprendizagem. Observe-se que tal posicionamento implica sinonimicamente em processo, o qual por sua vez envolve o método ou, melhor, uma metodologia.

Assim sendo, os métodos e as técnicas significam um ordenamento do ensino, implicando recusa à improvisação. Metaforicamente, os métodos e as técnicas são bússolas a guiar, teórica e praticamente, o ensino e a aprendizagem. Tal como o seu mostrador, expresso pela agulha, que indica o norte magnético, os métodos e as técnicas de ensino pautam a direção a ser seguida, bem como o processo a ser desenvolvido. Tratase de, através dos métodos e das técnicas, de imprimir uma racionalidade operacional ao próprio ensino. O inesperado, o que não foi previsto ou o que não foi preparado em termos de ensino, que visa a aprendizagem, significa a postura contrária ao método.

Em quarto lugar, cabe situar o lugar das tecnologias educativas no interior do trabalho didático. Duas dimensões podem ser distintas em vista de uma conceituação de tecnologia educacional, sendo que a primeira firma a seguinte posição: "[...] pode ser definida como aplicação sistemática de conhecimentos científicos e tecnológicos à solução de problemas educacionais ou como teorias e estudos específicos sobre o desenvolvimento e emprego de ferramentas, máquinas e procedimentos técnicos, em geral, em educação (FIDALGO \& MACHADO, 2000, verbete: tecnologia educacional).

Na seqüência, o mesmo verbete complementa em relação à segunda dimensão:

Mais especificamente, o termo tem sido utilizado para se referir à aplicação da tecnologia associada às ciências físicas e à engenharia na construção de instrumentos e equipamentos para fins de instrução. Estão compreendidos nesta categoria os equipamentos de projeção, gravadores, laboratórios de linguagem, televisão, máquinas de ensinar e sistemas de ensino baseados em computadores (FIDALGO \& MACHADO, 2000).

Desse modo, a referência básica à locução tecnologia educacional se estabelece em torno de um corpo de conhecimentos científicos e tecnológicos voltados para o ensino e a aprendizagem, distinguindo-se na segunda conceituação a referência aos instrumentos 
tecnológicos devotados à instrução. Portanto, o corpo de conhecimentos científicos e tecnológicos, bem como os instrumentos e equipamentos significam propriamente tecnologia educacional.

É dos anos de 1950 e 1960 o uso da referida locução, por parte de dois grupos:

(a) os especialistas em recursos audiovisuais e comunicação de massa aplicada à educação e (b) os psicólogos associados à linha identificada pelas denominações 'condicionamento operante' $e$ 'análise experimental do comportamento'. Nomes bem representativos dos grupos mencionados, são, certamente, no primeiro caso, James D. Finn e, no segundo, B.F. Skinner. (PFROMM NETO, 1976, p. 4)

Para o mesmo autor ainda, a origem da tecnologia da educação está referida aos recursos tecnológicos devotados ao campo educativo (projetores, gravadores, cinema, rádio, televisão etc), bem como à instrução programada e às máquinas de ensinar. "A essas duas facetas originais da tecnologia da educação devem ser acrescentadas outras [...]. Referimo-nos à análise de sistemas, à cibernética, à teoria e pesquisa em comunicação e a teoria e pesquisa em psicologia da aprendizagem" (PFROMM NETO, 1976, p. 5). Também esta é a posição de Maggio (2000, p. 27-31), ao se referir às origens da tecnologia educativa nos anos 1950. Em vista da compreensão da trajetória da denominação contida na locução tecnologia educativa, pode-se referi-la a

[...] duas vertentes fundamentais. Em primeiro lugar as concepções próprias das décadas dos anos 50 e 60 [respectivamente 1950 e 1960), as quais situavam a Tecnologia Educativa como o estudo dos meios como geradores de aprendizagem. Em segundo lugar, fundamentalmente a partir da década de 70 [1970], aquelas concepções que definem a Tecnologia Educativa por seu estudo do ensino como processo tecnológico. (MAGGIO, 2000, p. 25)

Dentre as tecnologias educativas, têm-se, cronologicamente situáveis, as lousas individuais, o quadro-negro - cuja emergência guarda relações com a configuracao do ensino simultâneo -, a lanterna mágica, o rádio, o cinematógrafo, o projetor de slides, o retroprojetor, o episcópio, a fita cassete, o gravador, o monitor de TV, o videocassete, e mais recentemente a lousa virtual viabilizada pelo power point, a smart board, entre outras. No entanto, outras tecnologias de pequena complexidade também estiveram ou estão estruturando o ensino e a aprendizagem, tais como o caderno, o lápis, a pena, o flanelógrafo, o álbum seriado, o globo, o compasso, o esquadro, a régua, o transferidor, o livro, a apostila, o mimeógrafo etc. Mais contemporaneamente, desde os anos de 1990, as TICs (tecnologias de informação e comunicação) vêm também ocupando o cenário educacional. Observe-se que tais tecnologias garantem a simultaneidade do ensino, dentre outros aspectos.

Um outro elemento a compor a noção de método de ensino, posto que está associado a ele, é a avaliação, uma vez que ela se configura associada ao controle do ensino, bem como às suas relações com o processo de aprendizagem. A avaliação "[...] como atividade prática aplicada sistematicamente aos processos educativos, começa a ser reconhecível desde o início do século XX [...]" (CARLINO, 1999, p. 29). No entanto, encontram-se práticas avaliativas desde as universidades medievais, bem como entre as 
orientações da Ratio Studiorum, centradas no disciplinamento e no controle (CARLINO, 1999), através dos exercícios escritos, das altercações entre os estudantes em torno dos conteúdos. Tais mecanismos de avaliação, nas instituições escolares jesuíticas, privilegiam a emulação, a competitividade, a premiação, promovendo interferências e relações com o processo de ensino e de aprendizagem.

No entanto, com a ampliação da escolarização, os mecanismos de avaliação se tornam sistemáticos, reservando-se para épocas anteriores o termo exame (CARLINO, 1999, p. 29-30). E nesse período de aplicação sistemática, está se configurando o ensino simultâneo, em resposta à ampliação da referida escolarização. Por conseguinte, em relação ao ensino e à aprendizagem, mas com ressonâncias no campo avaliativo de tal processo, estiveram em relação com a emergência do método intuitivo, depois do ativo.

Para além da materialização expressa por tais recursos tecnológicos de ensino e das relações que eles promovem ou conformam, os métodos e as técnicas de ensino são bússolas a orientar a atividade de ensino. Entretanto, a conformação maior dessa dimensão processual e operatória do ensino, ensejada pelos métodos, pelas técnicas e pelas tecnologias educativas, se faz pelos objetivos de ensino e pelas finalidades educativas, na verdade o norteamento maior do ensino e do processo avaliativo - ainda que este freqüentemente não seja assim compreendido ou assumido concretamente. Nesse patamar, são estes inteligíveis à luz da dimensão externa à aula, pela qual é compreensível como uma mediação cultural ou como mensageira que anuncia, mas que traz em si uma atribuição simbólica, da qual se reveste a escolarização como elemento civilizatório. Além disso, cabe ressaltar enfaticamente que em torno dos objetivos e das finalidades organizam-se as teorias pedagógicas, as concepções educativas, as visões de mundo, ainda que pouco explicitadas - talvez porque pouco refletidas - pelo professor e pelo projeto político-pedagógico de um curso ou de uma instituição.

Para finalizar esta seção: os objetivos são direcionados à operacionalização, o que não significa afirmar que não necessitam de mediações. Dessa forma, os referidos objetivos são mediatos, e não simplesmente imediatos. Por outro lado, os objetivos de ensino estão subsumidos pelas finalidades, posto que estas apontam "[...] na direção de um horizonte maior e mais amplo, carregado de uma fundamentação necessariamente filosófica, enquanto os objetivos mover-se-iam em busca da operacionalização concreta, sem com ela se confundir, mas orientando-a e permitindo caminhar na direção das finalidades" (ARAUJO, 2000, p. 97).

\section{O trabalho didático no Brasil dos anos de 1920: a aula, o ensino, o professor}

Nessa seção, estão aqui reunidos alguns posicionamentos de intelectuais brasileiros do campo da Educação nos anos de 1920 a 1930. São muitos os posicionamentos, por vezes díspares, veiculados por obras de caráter educacional e pedagógico. Trata-se de, através delas, verificar o protagonismo do professor, seja diante da organização do trabalho pedagógico, bem como diante do trabalho didático.

Observe-se que, em sentido etimológico, protagonista implica naquele que combate na primeira fila, termo derivado de prôtos ('primeiro') associado ao termo agónistês ('lutador, atleta'). Esse parece o sentido posto em ação pelas ilustrações aqui reunidas. Porém, o protagonismo do professor é colocado em questão, seja motivado pelo método, pela aula, pelo conteúdo, pelo ensino, pela formação, pela fragilidade da organização do trabalho pedagógico ou pelas técnicas de ensino, entre outros aspectos.

O posicionamento de Sampaio Doria (1920) a favor do profissionalismo docente, revela-se fundado numa orientação deísta: 
DAR AO PROFESSOR O VALOR QUE MERECE. Os professores que trabalham, constituem, entre as classes sociaes, a mais beneficente e mais benemérita. Na sua nobre obscuridade, nenhuma outra a excede em grandeza moral, nenhuma outra com tamanha responsabilidade. Deus, tendo creado o homem, commette ao educador a missão de lhe aperfeiçoar e aprimorar a creatura. Das mãos de Deus sahe a argila mysteriosa com uma evolução de corpo e de espírito, submettida a leis fataes. E o educador intervem nesta evolução, para completar, dentro das leis naturaes, a obra prima do Creador. Sem nenhum exaggero, o professor, que se dedica com amor e competência, é um mandatário de Deus no lavor divino da creação. E, contudo, ninguem há, entre os homens, tão desprotegido dos bons fados... Gloria, pois, senhores ao professorado pela sua missão sublime, pela sua dedicada bondade e pelo seu espírito de abnegação e sacrifício. (1920, p. 20-21)

O posicionamento de Antonio Carneiro Leão (1920) também a favor do profissionalismo docente, traduz em seu conjunto uma apologia ao ensino desenvolvido em São Paulo:

"Em São Paulo, a educação começou como devia. Foi a preparação de professores e o amor pela profissão de mestre, o que primeiro se procurou ao se desenvolver" (p. 91).

Em São Paulo, “[...] o ensino não é uma copia integral dos methodos americanos, como se poderia talvez suppor, porém uma adaptação mais ou menos feliz dos seus processos pedagógicos" (p. 93-94).

"Para conseguir resultado tão desvanecedor os professores não buscam apenas cumprir o seu dever, dando intelligentemente a sua aula, mas fazem um verdadeiro sacerdócio, interessando-se, com enthusiasmo, por tudo o que se refira à prosperidade da Escola, ao bem estar e ao progresso dos seus discípulos" (p. 95).

"Com professores assim competentes e affectuosos e os methodos mais objectivos e mais práticos, comprehende-se que os discípulos tenham effectivamente prazer em estudar, em conviver nesse ambiente de sympathia e de trabalho constructivo" (p. 96).

"Do jardim da infância e das escolas elementares principia-se a guiar a intelligencia, para caminhos práticos, exercitando-lhe os sentidos, conseguindo-lhe a collaboração do sentimento, incentivando-a no estimulo, affirmando-a na acção. É a instrucção, que ensina a agir agindo, onde o conhecimento se aprehende, vendo, observando, sentido, tocando e realizando. Não cesso de afirmar que, se o resto do paiz teimar nos velhos moldes de ensino theorico, dentro em pouco a mocidade paulista será não somente a mais productora e activa, senão também a mais intelligente, pelo menos no sentido de energia e de realização. É verdade que S. Paulo ainda não possue escolas para mais de cincoenta por cento de sua população escolar, mas os seus processos de instruir, o seu espírito pedagógico e a maioria dos seus professores são irrecusavelmente progressistas" (p. 99-100).

Conforme a perspectiva cronológica que reúne tais depoentes, novamente Sampaio Doria (1923), em uma outra obra, toma partido ao tecer críticas ao professor de então. Considerando que a ciência da educação envolve numerosos problemas - dentre eles, a organização das escolas, a fixação do que se deve ensinar, a seriação das matérias, a elaboração de programas, a confecção de horários -, a sua primeira parte discorre, por doze 
capítulos, sobre a "Methodologia didactica", no interior dos quais trata do método de ensino, de suas bases, da ação do professor e dos alunos. Basicamente, tal obra esta a fundamentar o método intuitivo.

Dado o teor dessa pesquisa, alguns trechos do capítulo VII, intitulado Praticas aberrativas, é bastante elucidativo: depois de comentar a respeito das aulas de botânica, de química, de física, de gramática, anuncia

[...] so mais uma aula. E de methodologia. O que logo notaes, e o tom pedagogo da voz do professor, e a sua sabedoria privilegiada de iniciado em mysterios cabalísticos. Os methodos, doutora elle, são quatro para fulano, seis sicrano, onze para beltrano. Fala em synthetico, com os olhos postos na synthese chimica. Fala em anlytico sem saberem os alumnos as leis de analyse. Fala em inductivo, sem desvendar o mecanismo da inducção. Fala em deductivo, sem explicar a estructura psychica do raciocínio. Não se preoccupa com os factos, sobre que versam os methodos: a acção do professor que dirige, a do alumno que se educa, as condições, sobre que se exerce a cooperação diretora do mestre. Parece que, de propósito, todos estes factos, constitutivos da matéria do methodo, são afastados da intelligencia do auditório, para maior gloria da sua immensa sabedoria pela consciência da difficuldade do que elle sabe (SAMPAIO DORIA, 1923, p. 51).

Depois de tais observações em torno dos métodos, generaliza que o problema pedagógico em torno da forma de ensino é generalizado nos níveis primário, secundário e superior:

Será que estas aberrações são privilegio da escola primaria e secundaria? Não. Nas escolas superiores, os estudos de pedagogia ainda se não acclimaram. Salva uma ou outra excepção, o methodo ahi é uma algaravia de phrases, ás vezes sonoras, vazias quase sempre. Repassam-se opiniões, ensinam-se pontos de vista, não se argumenta com razoes, não se mostram factos. A preoccupação das definições iniciaes é da pragmática. $\mathrm{O}$ ensino rola de abstracção em abstracção, entre nevoeiros de metaphysica, num eterno bate-boca doutrinário, entre rebeldias de grammatica e innocencia de estilo. O espírito, atordoado e cançado, do estudante, sae daquele recinto augusto, ignorando as realidades que fora conhecer. Já é proverbial dizer-se que, só com a pratica ulterior, se aprende, de quasi nada valendo o curso acadêmico. Mas a pratica do methodo pelos cathedraticos conseguiria a realidade do ensino acadêmico, como o exige o bom senso e a dignidade profissional. (SAMPAIO DORIA, 1923, p. 52)

No mesmo ano, uma expressão crítica ao ensino brasileiro se expressa através de Afrânio Peixoto (1923). Sua crítica dirige-se fundamentalmente ao ensino, para o que se faz necessária a aprendizagem para ensinar. Porém, começa por esclarecer que o título da obra, Ensinar a ensinar

[...] foi o nosso lema de combate - no Brasil ainda hoje se ensina, sem se ter aprendido a ensinar, por isso se ensina e se aprende tão mal... professores de ensino superior, de ensino secundário, e de ensino primário em muito lugar, ainda quando sabem, não sabem ensinar, porque não aprenderam e desdenham aprender... - esse é o maior mal da educação nacional - esse bem pode ser a divisa de uma propaganda... (1923, p. 6) 
Tais observações também se referem às escolas normais, incapazes de ensinar a ensinar:

Ainda há professores que não aprenderam sequer a ensinar, embora tenham cursado escolas apropriadas; são numerosos, conhecidos dos que lidam com eles e apontados com desvalia. Pior ainda, há essas escolas apropriadas, que chamamos normais, segundo o hábito francês, onde se devera ensinar a ensinar, mas cujos professores não o aprenderam, e, salvas raras excepções, não podendo portanto ensinar a ensinar: e esses, ninguém os acha mal, e toda a gente que assim é, e assim devem ser... (1923, p. 25)

Todavia, a crítica também reúne os profissionais liberais que se tornam professores sem formação para o ensino:

Toca as raias do disparate! Carecemos de professores públicos fundamos para os fazer uma escola normal, para a qual nomeamos, não os professores mais capazes desse nome, não os mais experimentados membros do magistério, mas a bacharéis em direito, doutores em medicina, engenheiros, militares, letrados, que, sem noção de pedagogia, sem possibilidade de a adquirir, se improvisam mestres de métodos, que totalmente ignoram! No Brasil, há escolas que se propõem a formar professores públicos, não me consta que exista alguma onde se formem os mestres desses futuros professores, capazes de os ensinarem a ensinar. Por isso, delas se diz, até em documentos públicos, que são liceus de preparatórios, com uma cadeira de pedagogia. (1923, p. 27)

São também registráveis as posições de Mario Pinto Serva (1924), na obra intitulada A Educação Nacional, homônima à de José Veríssimo de 1890. Mário Pinto Serva desenvolve aí uma abordagem de caráter social da educação brasileira de então. Em referência ao professor e ao seu trabalho didático, o capítulo "A miserável situação do ensino nacional", entre as páginas 26 e 30, traz algumas observações diversas daquelas de Carneiro Leão, ilustradas anteriormente:

No Estado de S. Paulo, é completa a anarchia do ensino. Nos outros Estados, para avaliar o que existe qualitativamente, basta dizer que não há escolas normaes e, portanto, não há professores capazes de ensinar proficientemente. Daí se pode concluir o resto (p. 26).

[....] o tão gabado progresso do Estado de S. Paulo em matéria de ensino. Lá está o Texas, na América do Norte, com egual população a S. Paulo, e tendo mais 800.000 alumnos nas suas escolas que o nosso glorioso e progressista Estado de S. Paulo! A differença provém tanto do maior tirocínio obrigatório nas escolas como de que nosso afamado Estado de S. Paulo apenas cerca de vinte por cento das crianças em edade escolar se acham effectivamente matriculadas nas escolas (p. 30).

Também em 1924, Orestes Guimarães, então inspetor federal das escolas subvencionadas em Santa Catarina, manifesta-se a favor de investiduras temporáriasda parte dos professores, justamente em vista do mau ensino:

Considerando [...] que o maior mal dos professores primários, salvo raras excepções, é que, uma vez nomeados para uma escola, se julgam 
desobrigados do preparo diário das lições, da convivência quotidiana com os livros; considerando, também, que os professores de emergência, os professores provisórios, a que se refere este capítulo, serão justamente aquelles (tudo nos leva a crer) que mais soffrerão desse mal, lembro o systema de investiduras temporárias. Com a adopção de tal systema, penso, em poucos annos existirão milhares de professores aptos e perfeitamente radicados ás zonas das próprias escolas em que tiveram de servir - professores que, pouco a pouco, se tornarão optimos elementos de combate ao analphabetismo. (1924, p. 99)

Também as escolas normais são inscritas entre as instituições que deveriam formar para o ensino, consideradas aqui como 'medíocres estabelecimentos':

As nossas Escolas Normaes, na sua grande maioria, prenhes de bellos
regulamentos e pomposos programmas, não passam de medíocres
estabelecimentos de ensino secundário ou médio. Nada mais. Basta
comparar-se os seus programmas com o numero dos seus docentes, para
que ressalte a sobrecarga a que estes estariam sujeitos se, de facto,
tomassem a sério as bellas disposições dos seus regulamentos; basta
comparar-se os horários, a duração das lições, o numero de matérias
semanaes distribuídas aos discentes, para que se tenha a impressao da
impossibilidade destes acompanharem proveitosamente o ensino; basta,
finalmente, verificar-se a forma por que os regulamentos normaes
predispõem as nomeações dos seus cathedraticos, o que é
importantíssimo, para que se deduza a forma por que são elles investidos
das elevadas funções de mestres de futuros mestres. Para essa gente
preparada, já se vê, o concurso é a mais falha e peior das provas... (1924,
p. 102-103).

Com relação às posições da Comissão da Associação Brasileira de Educação (A.B.E.), manifestam-se elas no interior dos depoimentos resultantes do Inquérito sobre $O$ Problema Universitário Brasileiro (1929), realizado em 1928.

Entre os componentes da referida Comissão, encontra-se Raul Leitão da Cunha, um dos co-organizadores do referido Inquérito. Para ele, o ensino superior brasileiro apresentava, então, deficiências muito importantes em vista da pedagogia universitária. E a aula é a instância em foco:

Quase todos nossos acadêmicos são visitantes efêmeros da Escola, principalmente porque nela não encontram atractivos interessantes, nem local apropriado para estudos e meditação. Assim, desobrigados da tarefa massadoira de assistir à aula, abandonam, apressados, o sitio em que deveriam permanecer as melhores horas do dia. (Cunha, 1929, p. 30)

Azevedo Amaral, também membro da referida Comissão, enfatizava que ao professor devia caber não somente uma atuação de um modo coletivo, mas também uma atuação individual. Caberá ao professor, ainda, presidir aos estudos, observar as dificuldades dos alunos, orientar os estudos, enfim caberá a ele realizar uma obra de educação intelectual. "O íntimo contacto entre o professor e o alumno, indispensável à efficiência da obra educativa, não deve se limitar à convivência nas salas de aulas e de estudo, nos gabinetes e laboratórios" (1929, p. 36-37). Trata-se de estreitá-las também através das associações acadêmicas, de modo que sejam destinadas " [...] a systematizar a cooperação de professores e alumnos na obra educativa [...]" (1929, p. 37). 
Também cabe destacar algumas questões de ordem didática advindas do líder escolanovista de então: Lourenço Filho (1930). Em carta datada de 10/03/1930, como resposta a João Hyppolito, que fora diretor da Escola Normal do Ceará, por ocasião da reforma escolanovista naquele Estado em 1922, pondera Lourenço Filho ao historiar os métodos de ensino tradicional, intuitivo e ativo:

\begin{abstract}
A princípio todo o ensino era verbal. Acreditava-se na magia da palavra, supunha-se mesmo que ela transmitisse as idéias. Foi ainda um pouco o ensino que aí eu encontrei (...). Depois do movimento filosófico da Renascença, apareceu a nova concepção de formação genética do espírito: nada está na inteligência que não tivesse passado pelos sentidos. Como consequiência direta, o ensino de coisas, pelas coisas, ou intuitivo. Quanto tempo levou a implantar-se? Séculos e séculos, e ainda não dominou todas as escolas. Do começo deste século para cá, essa concepção tende a ser substituída por outra, a de uma filosofia pragmatista (a verdade é a utilidade), e de uma filosofia vitalista (além das impressões sensoriais há um quid, em cada indivíduo, que plasmas as idéias a sua feição). O próprio pensamento para essa escola é ação: ação reduzida, mas ação. Ação reduzida e sistematizada pela linguagem, mas atividade. Daí, como conseqüência, não se pretender ensinar mais tão somente pela ação das coisas, mas ação do indivíduo, único capaz de organizar o espírito solidade, para o seu fim normal: dirigir a ação. (In CARVALHO, 2000, p. 4)
\end{abstract}

Em outra carta, também da mesma data, a Moreira de Sousa, então novo diretor da Instrução Pública, Lourenço Filho posiciona-se em defesa de seu trabalho em face da implantação do ensino ativo.Observe-se que estão em pauta os métodos intuitivo e ativo:

Digamos que eu não tenha razão. Digamos que a reforma não tenha feito senão ensino intuitivo. Isso já não seria pouco (...). Mas o ensino ativo é contra o ensino intuitivo? Não. É a lição dos mestres, e aliás, de bom senso. Na escola ativa a criança precisar agir. Mas agir sobre o quê? Sobre realidades, evidentemente, sobre coisas. (...) Nos seus artigos de polêmica, vejo que malsina demais o ensino intuitivo. Será talvez exagero consciente, para atrair a atenção para as novas idéias. Mas é uma concepção que não só desnorteia os professores, como, no caso, redunda em injustiça que o amigo certamente não desejou cometer. (In CARVALHO, 2000, p. 5)

Na mesma carta, afirma o método ativo como um capítulo da "escola nova da boa":

Obra notável que V. está fazendo é a tentativa de maior socialização da escola. Isso sim, é coisa que ninguém de bom senso pode discutir. Os centros de pais e mestres e as cooperativas escolares são uma obra notável. É escola nova da boa. O eixo da escola nova é exatamente a maior socialização do trabalho escolar. Escola ativa é apenas um de seus capítulos. (In CARVALHO, 2000, p. 5).

Antonio Firmino de Proença (1930), então inspetor geral do ensino do Estado de São Paulo, através de uma palestra na Escola Normal Livre de Jacareí, SP, também tece suas críticas às aulas de então, particularmente colocando no palco o professor: 
Em regra geral a grande preoccupação dos mestres é falar muito, para os alumnos ouvirem muito, escreverem muito e poderem reproduzir muito, tal qual nos velhos tempos. (1930, p. 28-29)

Depois de observar a respeito da rotina no ensino de então, observa em relação ao papel das disciplinas, História e Geografia:

Com relação á psychologia, á pedagogia e á didáctica é cedo para se manifestar a opinião pública, porem, podemos ter certeza de que ella virá desfavoravelmente, se nós nos mantivermos no actual ensino rotineiro. É necessário que os alumnos, os mestres, os paes e o publico em geral se convençam de que o estudo dessas disciplinas [história e geografia] é tão sério e tão difficil ou ainda mais serio e mais difficil do que o das sciencias mathematicas, physicas ou naturaes. Rehabilitemos, pois, a historia e a geographia e evitemos o desprestigio das sciencias básicas da nossa profissão. (1930, p. 29)

Todavia, o desencanto com o método ativo também se faz presente, além de sustentar que a aula é um monólogo que sempre triunfa:

Muitas e muitas vezes tenho assistido a aulas com todas as apparencias de aprendizado activo. Parece que o professor está conversando com a classe, fazendo-lhe perguntas, guiando-a na descoberta das verdades. Mas vem logo a desillusão. A aula é o monologo de sempre; as perguntas o professor as faz á classe, mas é elle mesmo quem as responde, convicto de eu está fazendo ensino activo e interessante. (1930, p. 31-32)

Porém, suas esperanças se renovam com a possibilidade de visualizar a mudança do ensino pela ação dos futuros normalistas:

Por agora, deixo-vos a condemnação da forma expositiva e a suggestão de uma nova forma, que há de ser a dominante no futuro. Nada perdereis, entretanto, em praticá-la desde já, numa ou noutra lição, a titulo de experiência. Uma cousa eu vos digo com certeza. É que o vosso methodo de ensino, a vossa attitude, a vossa linguagem serão o methodo de ensino, a attitude e a linguagem dos vossos alumnos quando forem professores. Dahi o cuidado que devem merecer de vossa parte todos os vossos actos como cathedraticos de uma escola normal. (1930, p 33-34)

\section{Considerações finais}

Para finalizar: os depoimentos se envolvem, em sua totalidade, com avaliações do trabalho didático, seja apelando para o profissionalismo docente, como o fazem Sampaio Dória (1920) e A. Carneiro Leão (1920) - este por sua elogiosa avaliação ao professor paulistano e à sua Escola Normal.

As críticas ao professor - e ao seu protagonismo - estão postas de várias formas: por Sampaio Dória (1923), uma voz de São Paulo, a respeito das aulas de metodologia de ensino, críticas estas generalizáveis para as escolas primárias, secundárias e superiores. Por Afrânio Peixoto (1923), do Rio de Janeiro, também a crítica é generalizada para todos os níveis de ensino, e a posição básica se refere à ausência de professores que não aprenderam a ensinar. Por Mário Pinto Serva (1924), através de sua obra publicada por uma editora de 
Pelotas, RS, que atribui ao Estado de São Paulo uma completa anarquia do ensino. Por Orestes Guimarães (1924), uma voz de Santa Catarina, uma crítica às escolas normais do ponto de vista organizativo. Por Raul da Cunha Leitão e Azevedo Amaral, vozes do Rio de Janeiro, organizadores e depoentes vinculados ao Inquérito de 1928, sobre o problema universitário brasileiro, duas posições: a do primeiro, referente à ausência de estudantes, considerados "visitantes efêmeros da Escola"; e a do segundo, que reflete uma posição a favor de uma relação intersubjetiva do professor e do aluno para além dos ambientes acadêmicos. Por Lourenço Filho (1930), uma defesa de sua obra escolanovista no Ceará, além das referências ao método intuitivo e ao método ativo. E finalmente também de 1930, a posição de Antonio Firmino de Proença, uma voz paulista, a criticar as aulas de então.

Em suma, as posições apresentam disparidades avaliativas diversas, além de serem representativas de vários estados naquela conjuntura entre os anos de 1920 e de 1930. Em debate estavam a organização do trabalho pedagógico e do trabalho didático, posto que ambos solicitavam associações entre si, em vista da educação escolar.

O período em apreço guarda relações com vários movimentos de ordem educacional: grupos escolares, escolas normais, emergência concreta de duas universidades - a do Rio de Janeiro em 1920 e a de Minas Gerais em 1927, as futuras UFRJ e UFMG. O movimento escolanovista já estava organizado em dez estados em 1930 em termos de legislação estadual: São Paulo, Ceará, Rio de Janeiro, Bahia, Paraná, Rio Grande do Norte, Minas Gerais, Mato Grosso, Pernambuco e Espírito Santo.

A vigência do ensino simultâneo trazia em seu bojo, no período dos anos de 1920, os métodos tradicional, intuitivo e ativo. Grassavam técnicas de ensino associadas ao método ativo, além daquelas herdadas dos métodos tradicional e intuitivo. Em termos de tecnologia educativa, uma amostra pode ser verificada pelo que acontecia em Minas Gerais, conforme documentam as Mensagens dos Presidentes do Estado de Minas Gerais entre 1920 e 1927: 


\begin{tabular}{|c|c|c|c|c|c|c|c|c|}
\hline $\begin{array}{c}\text { Tecnologias educativas e } \\
\text { mobiliário escolar }\end{array}$ & 1920 & 1921 & 1922 & 1923 & 1924 & 1925 & 1926 & 1927 \\
\hline Armários & - & - & - & - & 59 & - & - & - \\
\hline Bandeiras nacionais & - & - & - & - & - & - & 500 & - \\
\hline Bibliotecas & - & - & - & - & Sim & - & 5950 & 53 \\
\hline Caixas de sólidos geométricos & - & - & - & - & - & 42 & - & - \\
\hline Cadeiras com assento de palhinha & - & - & - & - & 192 & - & - & - \\
\hline Carteiras & - & Sim & - & 3441 & 2200 & 7567 & 12608 & 8162 \\
\hline Carteiras contratadas & - & - & - & - & - & - & 15000 & - \\
\hline Coleção de minerais e vegetais & - & - & - & - & - & - & Sim & - \\
\hline Contadores & - & - & - & - & - & 231 & - & - \\
\hline Contadores mecânicos & - & - & - & - & 11 & - & - & - \\
\hline Compassos & - & - & - & - & - & 52 & - & - \\
\hline Esquadros & - & - & - & - & - & 63 & - & - \\
\hline Filmes escolares & - & - & - & - & - & - & - & - \\
\hline Gabinetes & - & - & - & - & - & - & Sim & - \\
\hline Gizes & Sim & - & - & - & - & $8000 \mathrm{cxs}$. & - & - \\
\hline Globos geográficos & - & - & - & - & - & 41 & - & - \\
\hline Jogos infantis & - & - & - & - & Sim & - & - & - \\
\hline Laboratórios & - & - & - & - & - & - & Sim & - \\
\hline -Livros & Sim & Sim & - & - & - & - & - & - \\
\hline Livros de leitura & - & - & Sim & - & - & 181700 & 210500 & 212275 \\
\hline Livros de leitura $^{\mathrm{i}}$ & - & - & - & - & - & - & - & 7308 \\
\hline Livros didáticos & 213.850 & - & - & - & $4592^{\mathrm{ii}}+9650^{\mathrm{iii}}$ & - & - & - \\
\hline Mapas da América do Norte & - & - & - & - & - & 18 & - & - \\
\hline Mapas da Europa & - & - & - & - & - & 20 & - & - \\
\hline Mapas de Minas Gerais & - & - & - & - & - & 625 & - & - \\
\hline $\begin{array}{l}\text { Mapas de Minas Gerais, do } \\
\text { Brasil e da Europa }\end{array}$ & - & - & - & - & Sim & - & - & - \\
\hline Mapas do Brasil & - & - & - & - & - & 352 & - & - \\
\hline Machinas de cinema & - & - & - & - & - & - & 4 & - \\
\hline Máquinas de costura & - & - & - & - & - & - & 35 & - \\
\hline Mesa para professores. & - & - & - & - & 60 & - & - & - \\
\hline Mobílias para gabinete & - & - & - & - & - & - & 13 & - \\
\hline Museus escolares & - & - & - & - & Sim & - & Sim & 141 \\
\hline Organiz. de bibliotecas infantis & - & - & - & - & - & - & - & - \\
\hline Quadros-negros & - & - & 63 & 115 & 75 & 220 & 306 & - \\
\hline Pequenos utensílios para desenho & - & - & - & - & Sim & - & - & - \\
\hline Planisférios & - & - & - & - & - & 10 & - & - \\
\hline Quadros de história natural & - & - & - & - & Sim & - & - & - \\
\hline Réguas & - & - & - & - & - & 137 & - & - \\
\hline Relógios & - & - & - & - & - & - & 31 & - \\
\hline Revista do ensino & - & - & - & - & Sim & - & - & - \\
\hline Sofás com assento de palhinha & - & - & - & - & 10 & - & - & - \\
\hline Telas americanas & - & - & - & - & 70 escolas & - & - & - \\
\hline Transferidores & - & - & - & - & - & 29 & - & - \\
\hline
\end{tabular}

Fonte: Elaboração do autor com base nas Mensagens dos Presidentes do

Estado de Minas Gerais de 1920 a 1927.

Em suma, aqui estão alguns aspectos dos bastidores da sala de aula, bem como a constituição da aula de então. Observa-se que o debate em torno desta coloca dificuldades a serem resolvidas pela organização do trabalho pedagógico - seja em nível nacional, estadual ou mesmo local, ou ainda institucional - bem como pela organizado do trabalho didático. Pode-se inclusive afirmar que as controvérsias em torno do ensino, do método ou da aula propriamente dita revelam disputas em torno dos métodos tradicional, intuitivo e ativo, bem como em torno das técnicas de ensino e das tecnologias educativas a eles associados. Revelam-se, pelos posicionamentos, perturbações advindas da própria organização escolar brasileira em vista dos diferentes níveis de ensino - primário, secundário e superior -, bem como em torno das escolas normais, adstritas à formação do professor.

Para concluir, uma posição poética também leva a pensar também na escola de então: "ADEUS COLÉGIO, adeus vida/ vivida sob inspeção,/ dois anos jogados fora ou dentro de um caldeirão/ em que se fritam destinos/ e se derrete a ilusão./ Já preparo minha trouxa/ e durmo na solidão./ Amanhã cedo retiro-me,/ pego o trem da Leopoldina,/ vou ser de novo mineiro./ [...] (DRUMMOND DE ANDRADE, p. 681-682). Trata-se este de um depoimento poético a respeito de sua experiência como aluno interno no Colégio Anchieta, jesuítico, de Nova Friburgo, RJ, do qual foi expulso em 1919. Um depoimento em que sua interlocução com a escola foi mal sucedida, porém certamente associada às discussões educacionais e pedagógicas veiculadas pelas obras, aqui ilustradas, entre 1920 e 1930. 


\section{Referências}

ALVES, Gilberto. O trabalho didático na escola moderna. Campinas, SP: Autores Associados, 2005.

AMARAL, Ignácio M. Azevedo. O professor e o alumno. In O problema universitário brasileiro: Inquérito promovido pela Secção de Ensino Technico e Superior da Associação Brasileira de Educação. Rio de Janeiro: Encadernadora, 1929, p. 32-44.

ARAUJO, José Carlos S. Do quadro-negro à lousa virtual: técnica, tecnicismo e tecnologia. In VEIGA, Ilma Passos Alencastro (org.). Técnicas de ensino: novos tempos, novas configurações. Campinas, SP, Papirus, 2006, p. 13-48.

. Ser professor: da divisão do trabalho à organização do trabalho pedagógico e do trabalho didático. Cadernos de História da Educação, Uberlândia, MG, 8(1): 137-156, 2009.

BARTHES, Roland. A aula. 12a . Edição. São Paulo: Cultrix, 2004.

BUISSON, Fernand (dir.). Nouveau Dictionnaire de Pédagogie et d'Instruction Primaire. Paris: Librairie Hachette, 1911, 2087 páginas.

CARNEIRO LEÃO, A. S. Paulo em 1920. Rio de Janeiro: Annuario Americano, 1920.

CARVALHO, Marta Maria Chagas de. Modernidade pedagógica e modelos de formação docente. São Paulo em Perspectiva, São Paulo, 14, 1: 1-8, jan.-mar. 2000.

CERVO, Amado Luiz \& BERVIAN, Pedro Alcino. Metodologia científica para uso dos estudantes universitários. São Paulo, Editora McGraw-Hill do Brasil, 1976.

CUNHA, Raul Leitão da. A crise actual do ensino, no Brasil - seus factores e seus aspectos. In O problema universitário brasileiro: Inquérito promovido pela Secção de Ensino Technico e Superior da Associação Brasileira de Educação. Rio de Janeiro: Encadernadora, 1929, p. 26-31.

DRUMMOND DE ANDRADE, Carlos. Poesia e Prosa organizada pelo autor. Rio de Janeiro: Editora Nova Aguilar, 1988.

FIDALGO, Fernando \& MACHADO, Lucília (editores). Dicionário da Educação Profissional. Belo Horizonte, Núcleo de Estudos sobre Trabalho e Educação, FAE/UFMG, 2000.

FREITAS, Luiz Carlos de. Crítica da organização do trabalho pedagógico e da didática. Campinas, SP: Papirus, 1995.

GUIMARÃES, Orestes. Suggestões sobre a Educação popular no Brasil. Florianópolis: Livraria Moderna, 1924.

HERBART, Johann Friedrich. Esbós per a um curs de pedagogia. Trad. De Joseph M. Revista HISTEDBR On-line, Campinas, n.35, p. 250-271, set.2009-ISSN: 1676-258 269 
Bordas. Vic, Espanha: Eumo Editorial, 1987.

KANT, Immanuel. O conflito das faculdades. Lisboa: Edições 70, 1993.

LAKANAL, J. Rapport sur l'établissement des écoles normales. Paris, De l'Imprimerie Nationale, 1794.

LIBÂNEO, José Carlos. Organização e gestão da escola: teoria e prática. $5^{\text {a }}$. edição revista e ampliada. Goiânia, GO: Editora Alternativa, 2004.

LOURENÇO FILHO. Tendências da educação brasileira. São Paulo: Melhoramentos, 1940.

LUZURIAGA, Lorenzo. Diccionario de Pedagogia. $3^{\text {a }}$. edição. Buenos Aires: Editorial Losada, 2001.

MENUCCI, Sud. A crise da educação brasileira. Digitalização da 2a . Edição de 1934. São Paulo: Editora Piratininga, 2006.

MORA, José Ferrater. Diccionario de Filosofía. $4^{\text {a }}$ edição. Madri, Alianza Editorial, 1982.

OLIVEIRA, Antonio de Almeida. O ensino público. Brasília, DF, Senado Federal, 2003.

O PROBLEMA UNIVERSITÁRIO BRASILEIRO: Inquérito promovido pela Secção de Ensino Technico e Superior da Associação Brasileira de Educação. Rio de Janeiro: Encadernadora, 1929.

PEIXOTO, Afrânio. Ensinar a ensinar: ensaios de Pedagogia aplicada à educação nacional. Rio de Janeiro: Francisco Alves, 1923.

PROENÇA, Antonio Firmino de. Palestras pedagógicas. São Paulo: Directoria Geral da Instrucção Publica. Departamento de Publicidade, 1930, 34 p.

SAMPAIO DÓRIA, A. de. Discurso proferido pelo Sr. Dr. Antonio Sampaio Dória, recentemente nomeado director do Ensino em sessão solenne effectuada no dia 24 de maio no Salão Nobre do Jardim da Infância. São Paulo: Augusto Siqueira \& Cia., 1920. . Como se ensina. São Paulo: Monteiro Lobato \& Co. Editores, 1923, p. 51-52).

SANTOS, Oder J. A organização do processo de trabalho pedagógico. In: Anais da IV Conferência Brasileira de Educação, n. 1. Goiânia: Cortez e Moraes, 1986, p. 408-411.

SERVA, Mário Pinto. A educação nacional. Pelotas, RS: Echenique \& Comp., 1924.

SEVERINO, A.J. Educação, sujeito e história. São Paulo: Olho d’Água, 2001.

ULMANN, Jacques. La nature et l'éducation: l'idée de nature dans l'éducation physique et dans l'éducation morale. Paris, Klincksieck, 1987. 
VALDEMARIN, Vera Maria. Estudando as lições de coisas: análise dos fundamentos filosóficos do método de ensino intuitivo. Campinas, Autores Associados, 2004.

VEIGA, Ilma Passos Alencastro. Ensino e avaliação: uma relação intrínseca à organização do trabalho pedagógico. In: VEIGA, Ilma Passos Alencastro (org.). Didática: o ensino e suas relações. Campinas, SP: Papirus, 1996, p. 127-169.

VEIGA, Ilma Passos Alencastro. Organização didática da aula: um projeto colaborativo de ação imediata. In: VEIGA, Ilma Passos Alencastro (org.). Aula: gênese, dimensões, princípios e práticas. Campinas, SP: Papirus, 2008, p. 267-298.

VON ZUBEN, Newton Aquiles. Sala de aula: da angústia de labirinto à fundação da liberdade. In RÉGIS DE MORAIS, J.F. (org.). Sala de aula: Que espaço é esse? $19^{a}$ edição. Campinas: Papirus, 2005, p. 123-129.

WACHOWICZ, Lílian A. O método dialético na didática. Campinas, SP: Papirus, 1989.

Notas:

\footnotetext{
${ }^{\mathrm{i}}$ Destinados às escolas municipais.

ii Destinados a 49 municipalidades.

iii Destinados aos grupos escolares recém instalados em 1924.
}

Artigo recebido em: 10/09/2009

Aprovado para publicação em: 25/09/2009 